\title{
Meta-Analysis the Effect of Oral and Injection Contraceptives on Breast Cancer
}

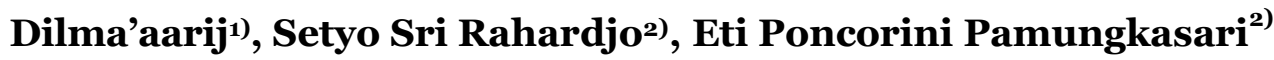 \\ 1)Masters Program in Public Health,Universitas Sebelas Maret \\ ${ }^{2)}$ Faculty of Medicine,Universitas Sebelas Maret
}

\section{ABSTRACT}

Background: Oral contraceptives and injections are the main risk factors for breast cancer. The content of the hormones estrogen and progesterone in oral contraceptives and progestin in injection contraceptives can affect uncontrolled growth of breast tissue, leading to breast cancer. This study aims to analyze the magnitude of the effect of oral contraceptives and injection on the incidence of breast cancer by means of a meta-analysis study.

Subjects and Method: This was a systematic review and meta-analysis conducted with PRISMA flow diagrams. Search for articles through journal databases includes: PubMed, Science Direct, and Google Scholar by selecting articles published in 2010-2020. The keywords used were "Women Aged 15-80 Years" AND "Contraceptive Pills" OR "Birth control injections" AND "Breast Cancer". The inclusion criteria were full text articles with observational study design, articles in English, and multivariate analysis used with adjusted odds ratios. Articles that meet the requirements are analyzed using the Revman 5.3 application.
Results: A meta-analysis of 15 observational studies showed that oral contraceptives had a 1.30 times risk of developing breast cancer compared with women using non-hormonal contraceptives $(\mathrm{aOR}=1.30 ; 95 \% \mathrm{CI}=1.13$ to $1.50 ; p=0.0002)$. A meta-analysis of 6 observational studies showed injectable contraceptives had a 1.37 times risk of developing breast cancer compared to using non-hormonal contraceptives $(\mathrm{aOR}=1.37 ; 95 \% \mathrm{CI}=1.09$ to $1.71 ; \mathrm{p}=0.006)$.

Conclusion: Oral hormonal contraceptives and injections have a weak effect on the incidence of breast cancer.

Keywords: injection contraception, oral contraception, breast cancer, meta-analysis

\section{Correspondence:}

Dilma'aarij Riski Agustia. Masters Program in Public Health. Universitas Sebelas Maret, Jl.Ir. Sutami 36A, Surakarta 57126, Jawa Tengah, Indonesia. Email: dilmarij@gmail.com. Mobile: 082230100871.

\section{Cite this as:}

Dilma'aarij, Rahardjo SS, Pamungkasari EP (2021). Meta-Analysis the Effect of Oral and Injection Contraceptives on Breast Cancer. J Matern Child Health. 06(02): 238-249. https://doi.org/10.26911/thejmch.2021.06.02.11.

cc) (7) (2) Journal of Maternal and Child Health is licensed under a Creative Commons

Attribution-NonCommercial-ShareAlike 4.0 International License.

\section{BACKGROUND}

Cancer is a type of non-communicable disease and has an increasing number of cases every year (Ayu et al., 2015). Nationally and globally, breast cancer is a case that is the biggest contributor to death in women. Global data shows that there are 58,256 cases or $16.7 \%$ of the total 348,809 cases. In addition, the 2018 Globocan data reports that there are as many as 2.1 million new cases and is expected to continue to increase every year. Breast cancer is the most common cancer suffered by women in the world with a cumulative risk of 4.61 and a death rate of 22,692 people (Globocan, 2020).

Breast cancer is a disease that is a risk for every woman in the world. One of these non-communicable diseases, should not be ignored by individuals, communities and 
stakeholders in the health sector. Breast cancer is becoming increasingly difficult and has a long-lasting treatment stage. According to the American Cancer Society, breast cancer is affected by the presence of the hormones estrogen and progesterone in women. High exposure to the hormone estrogen is one of the factors that can increase the incidence of breast cancer risk in women. Based on the results of previous studies, the risk factors for breast cancer are multifactorial and interrelated with one another. Several factors are thought to have a big influence on the occurrence of breast cancer. Elsharkawy said that the risk factors for breast cancer include family history, use of hormonal contraceptives, age of menarche, physical activity, age and obesity (Yulianti, 2016). In another study, it was stated that one of the causes of breast cancer is the use of hormonal contraceptives for a long time.

Several studies have been conducted to determine and estimate the effect of the use of oral hormonal contraceptives and injection on the incidence of breast cancer, including by Morch et al. (2017) which shows that women who use oral hormonal contraceptives have 1.2 times the risk of developing breast cancer than those who have never used hormonal contraceptives. Busund et al. (2018) also stated that there was a significant relationship with the use of oral hormonal contraceptives, where the risk of experiencing breast cancer was $\mathbf{1 . 0 7}$ times. Alsolami et al. (2019) stated that the use of oral hormonal contraceptives has a 6.78 times risk of experiencing breast cancer when compared to women using non-hormonal contraceptives. According to $\mathrm{Li}$ et al. (2012), women who use injection contraception have a 2.2 times risk of developing breast cancer. Shapiro et al. (2021), women aged 20-54 years who use injectable hormonal contraceptives have a
0.9 risk of developing breast cancer compared to women who do not use hormonal contraceptives. Ayu et al. (2015) stated that using injection contraceptives had a 3.3 times risk of developing breast cancer compared to women who used nonhormonal contraceptives.

Based on the high incidence of breast cancer in women, this is due to the hormonal content in the body and requires proper prevention and treatment. In addition, a more comprehensive study is needed from the various results of previous primary studies on the effect of the use of oral and injection hormonal contraceptives on the incidence of breast cancer. The data obtained by the researcher will be analyzed using a meta-analysis study design, which is an epidemiological study that provides the strongest evidence of causality by combining and statistically aggregating the results of a number of independent primary studies that could be combined. In the meta-analysis research the researcher also tested the same hypothesis, in the same way so that a quantitative summary was obtained (Murti, 2018), which will finally be analyzed with the help of the RevMan 5.3 software which has previously been carried out by a synthesis of study results to reduce bias.

\section{SUBJECTS AND METHOD}

\section{Study Design}

The study design used in this study is a systematic review and meta-analysis, using the PRISMA flow diagram guidelines. Search for articles was carried out using journal databases which include: PubMed, Google Scholar and Science Direct. The keywords used were "women aged 15-80 years" OR "women of menopause" OR "women of premenopause" OR "women of postmenopause" OR "hormonal birth control acceptors" AND "hormonal contra- 
ception" OR "birth control injections "OR" contraceptive pills "AND" breast cancer".

\section{Inclusion Criteria}

In this study, the inclusion criteria were full text articles using an observational study design, namely cohort and case control, articles in English, the analysis used was multivariate with adjusted odds ratio, the research subjects were women aged $15-80$ years, the intervention was oral hormonal contraception. and the injection and outcome was breast cancer.

\section{Exclusion Criteria}

The exclusion criteria in this study included articles published before 2010 and languages other than English.

\section{Operational Definition of Variables} In formulating the research problem here, the researcher uses PICO. The population is women aged $15-80$ years. Intervention is oral and injection hormonal contraceptives, with comparison of non-hormonal contraceptives and the outcome is breast cancer.

Oral hormonal contraceptives are contraceptives that are being used or a history of use of hormonal contraceptives by women aged 15-80 years in the form of oral contraceptives.

Injectable hormonal contraceptives are contraceptives currently in use or a history of use of hormonal contraceptives by women aged 15-80 years in the form of injection contraceptives.

Breast cancer is a cell that grows abnormally in breast tissue and is diagnosed by radiological examination.

\section{Instruments}

An assessment of the quality of research articles was carried out using the Critical Appraisal Skills Program (CASP) for Cohort Study, Critical Appraisal Checklist for case control (CEBMa, 2014).

\section{Data Analysis}

The Review Manager application (RevMen 5.3) was used in analyzing the data in this study. The results of data analysis are in the form of the effect size and heterogeneity of the study, which later will interpret the results of the analyzed data in the form of a forest plot and funnel plot.

\section{RESULTS}

Research from primary studies related to the effect of the use of oral and injection hormonal contraceptives on the incidence of breast cancer consisted of 21 studies from 6 studies from the Asian continent, 5 studies from the continent of Europe, 5 studies from the continent of Africa and 5 studies from the continent of North America. Figure 1 shows the areas the articles were drawn in that match the inclusion criteria. Furthermore, the researchers conducted an assessment of the quality of the articles (Tables 1 and 2). Meanwhile, table 3 shows that there are 5 articles of cohort studies and 16 articles of case control studies. The results showed that oral and injection hormonal contraceptives had an effect on the incidence of breast cancer.

The search for articles was carried out using a database based on PRISMA. The flow diagram can be seen in Figure 2. 
Dilma'aarij et al./ The Effect of Oral and Injection Contraceptives on Breast Cancer

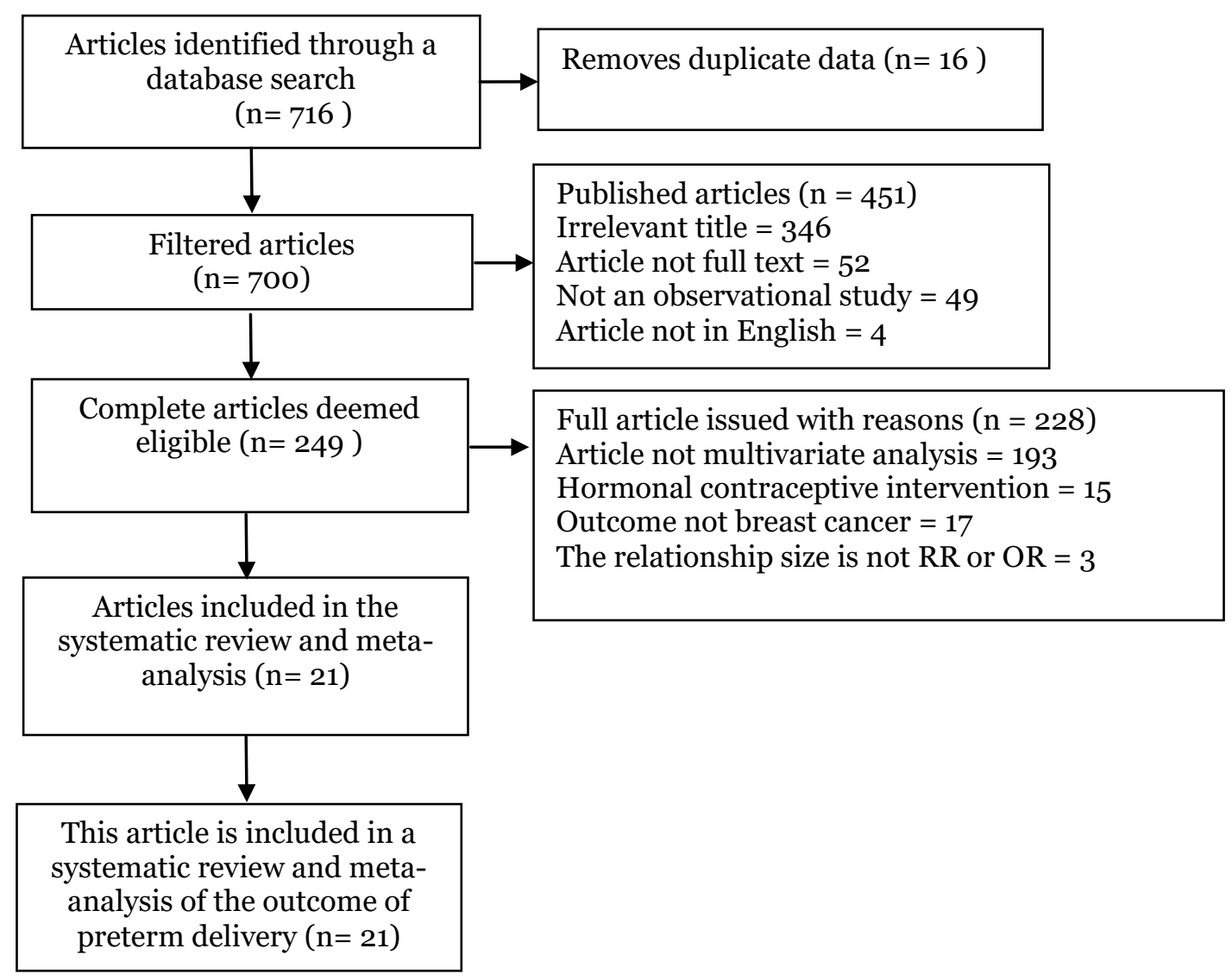

Figure 2. PRISMA flow diagram

Assessment of the quality of the study was carried out using the Critical Appraisal Checklist for Cohort Study and the Critical Appraisal Checklist for ase control (CEBMa, 2014). After assessing the quality of the study, 21 articles included in the quantitative synthesis meta-analysis were analyzed using RevMan 5.3. This is a table of results assessing the quality of studies with oral and injection hormonal contraceptive interventions and breast cancer outcomes.

\section{Forest plot}

Interpretation of the results from the metaanalysis process can be seen through a forest plot. Figure 3 shows that the results of the subgroup analysis in the cohort study showed that oral hormonal contraceptives had a 1.16 times risk of developing breast cancer compared with the use or history of non-hormonal contraceptives and were statistically significant $(\mathrm{p}=0.001)$. The heterogeneity of the research data showed $\mathrm{I}^{2}=0 \%$. Meanwhile, the results of the subgroup analysis in a case control study showed that oral hormonal contraceptives had a 1.48 times risk of developing breast cancer compared to the use or history of non-hormonal contraceptives and were statistically significant $(\mathrm{p}=0.002)$. The heterogeneity of the research data showed I $2=81 \%$. So that the distribution of data is expressed as heterogeneous (random effect model).

\section{Funnel Plot}

A funnel plot is a plot that depicts the estimated effect size of each study on the estimate of its accuracy which is usually the standard error.

Based on Figure 4, the cohort study does not show publicity as indicated by the 
Dilma'aarij et al./ The Effect of Oral and Injection Contraceptives on Breast Cancer

symmetrical distribution of the right and left plots where 1 plot is on the right, 1 plot is in the middle and 3 plots are on the left. The case control study also showed no publication bias which was indicated by the symmetrical distribution of the right and left plots where there were 4 plots on the left, 4 plots on the right and 2 plots in the middle. The plot on the left of the graph appears to have a standard error between 0 and 3 and the plot on the right has a standard error between 0 and 1.

Odts Reatio

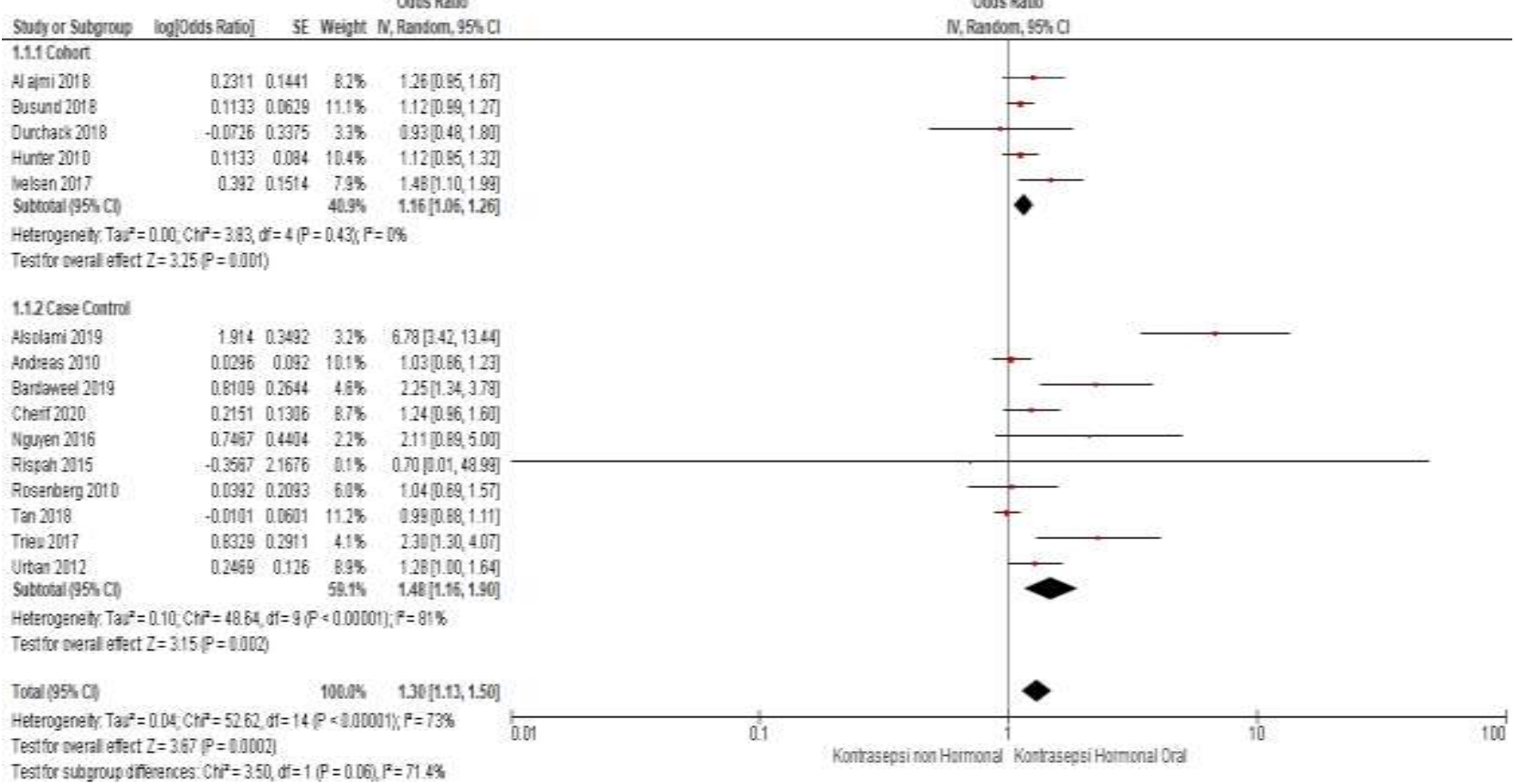

Figure 3. Forest plot of the effect of hormonal contraception oral against breast cancer

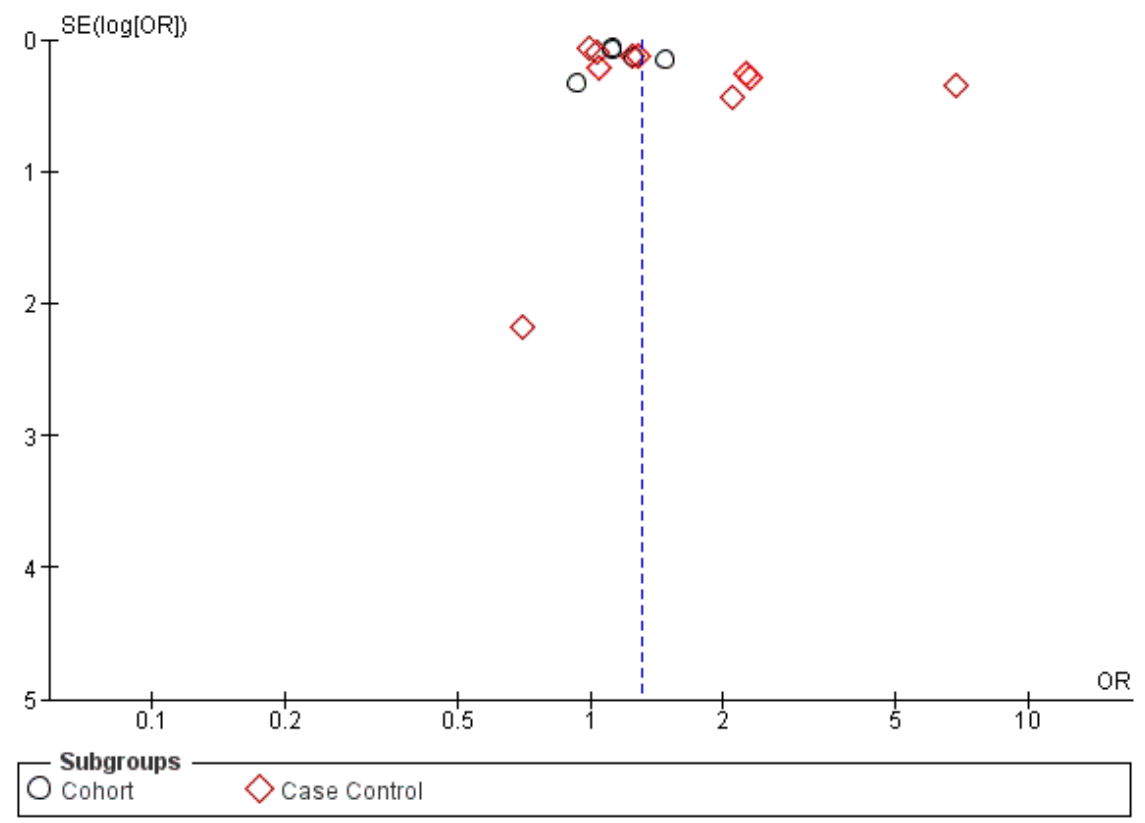

Figure 4. Funnel plot of the effect of hormonal contraception oral against breast cancer 
Dilma'aarij et al./ The Effect of Oral and Injection Contraceptives on Breast Cancer

\section{Forest plot}

Interpretation of the results from the metaanalysis process can be seen through a forest plot. Figure 4.6 shows that the results of the analysis in a case control study showed that injectable hormonal contraception had a 1.31 times risk of developing breast cancer compared to the use or history of non-hormonal contraception and was statistically significant $(p=0.006)$. The heterogeneity of the research data showed $\mathrm{I}^{2}=66 \%$. So that the distribution of data is expressed as heterogeneous (random effect model).

\begin{tabular}{|c|c|c|c|c|c|c|c|c|c|}
\hline Study or Subgroup & log[Odds Ratio] & SE & Weight & $\begin{array}{l}\text { Odds Ratio } \\
\text { IV, Random, } 95 \% \mathrm{Cl}\end{array}$ & \multicolumn{5}{|c|}{$\begin{array}{l}\text { Odds Ratio } \\
\text { N, Random, } 95 \% \text { Cl }\end{array}$} \\
\hline Amadou, 2013 & 0.077 & 0.0342 & $32.0 \%$ & $1.08[1.01,1.15]$ & & & \multirow[t]{2}{*}{$=$} & & \\
\hline Crishtoper, 2012 & 0.7885 & 0.3093 & $9.7 \%$ & $2.20[1.20,4.03]$ & & & & & \\
\hline Heikkinen, 2015 & 0.1989 & 0.1496 & $21.1 \%$ & $1.22[0.91,1.64]$ & & & $\longrightarrow$ & & \\
\hline Mehdi, 2019 & 0.7031 & 0.2657 & $11.9 \%$ & $2.02[1.20,3.40]$ & & & $\longrightarrow$ & & \\
\hline Rispah, 2015 & 1.5041 & 0.9494 & $1.4 \%$ & $4.50[0.70,28.93]$ & & & \multirow{2}{*}{$\longrightarrow$} & & \\
\hline Urban, 2012 & 0.27 & 0.1227 & $23.9 \%$ & $1.31[1.03,1.67]$ & & & & & \\
\hline \multicolumn{3}{|c|}{ Total $(95 \% \mathrm{Cl})$} & $100.0 \%$ & $1.37[1.09,1.71]$ & & & & & \\
\hline \multicolumn{5}{|c|}{$\begin{array}{l}\text { Heterogeneity: } \text { Tau }^{2}=0.04 ; \mathrm{Chi}^{2}=14.92, \mathrm{df}=5(P=0.01) ;\left.\right|^{2}=66 \% \\
\text { Test for overall effect: } Z=2.72(P=0.006)\end{array}$} & $\begin{array}{lr}1 & 1 \\
0.1 & 0.2 \\
\text { Kontrasep }\end{array}$ & $\begin{array}{ll}1 \\
0.5 \\
\text { Hor }\end{array}$ & Kontrase & $\begin{array}{l}1 \\
5 \\
\text { si }\end{array}$ & 10 \\
\hline
\end{tabular}

Figure 5. Forest plot of the effect of injectable hormonal contraception on breast cancer

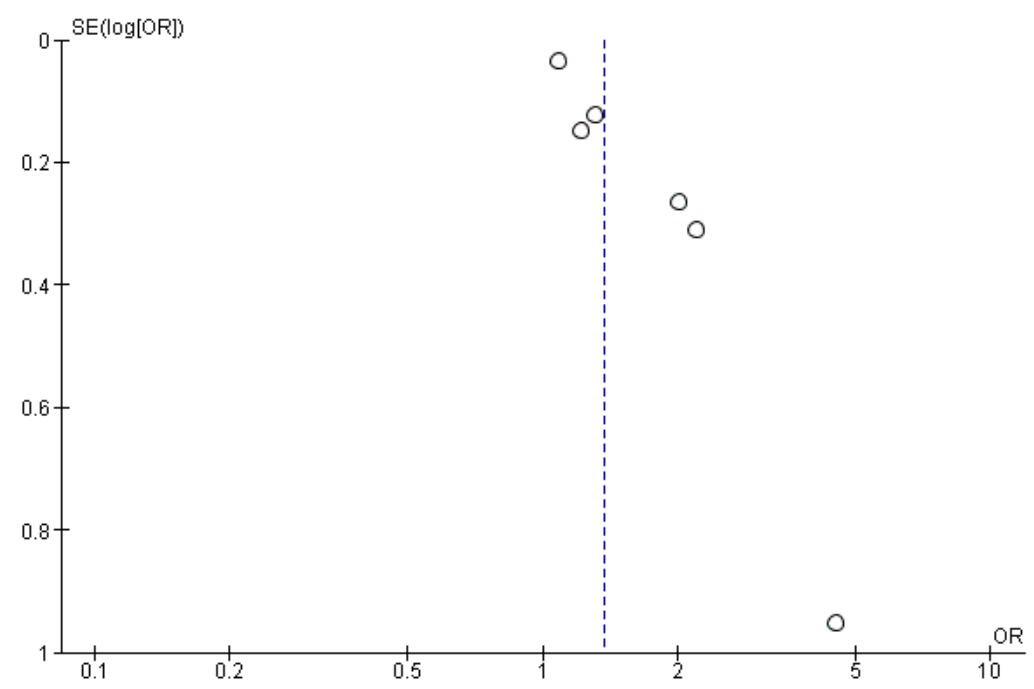

Figure 6. Funnel plot of the effect of injection hormonal contraception on breast cancer

\section{Funnel Plot}

A funnel plot is a plot that depicts the estimated effect size of each study on the estimate of its accuracy which is usually a standard error. Based on Figure 7, the case control study shows a publication bias as indicated by the symmetrical distribution of the right and left plots where 3 plots are on the right and 3 plots are on the left. The plot on the left of the graph appears to have a standard error between 0 and 0.2 and the plot on the right has a standard error between 0.2 and 1

\section{DISCUSSION}

This systematic review study and metaanalysis discusses the effect of oral and injection hormonal contraceptives on breast cancer incidence. Independent variables were analyzed for women aged $15-80$ 
years who used or had a history of use of oral hormonal contraceptives and injections. The dependent variable in this study is breast cancer. The results of the primary study conducted show that the epidemiological study design with a larger number of samples, besides that there are demographic characteristics that vary in different countries, this will be the basis for concluding that women who use or have a history of use of oral hormonal contraceptives statistics on breast cancer.

Breast cancer is a disease that is a risk for every woman in the world. One of these non-communicable diseases, should not be ignored by individuals, communities and stakeholders in the health sector. Breast cancer is becoming increasingly difficult and has a long treatment stage (Ministry of Health, 2019).

According to the American Cancer Society, breast cancer is influenced by the presence of the hormones estrogen and progesterone in women. High exposure to the hormone estrogen is one of the factors that can increase the incidence of breast cancer risk in women. Based on the results of previous studies, the risk factors for breast cancer are multifactorial and interrelated with one another. Several factors are thought to have a big influence on the occurrence of breast cancer. Elsharkawy said that the risk factors for breast cancer include family history, use of hormonal contraceptives, age of menarche, physical activity, age and obesity (Yulianti, 2016).

This study used a previous primary study that controlled for confounding factors, this can be seen based on the study inclusion requirements, namely using multivariate analysis and adjusted odds ratio (aOR) statistical results. According to Murti (2018), confounding factors are a mixture of estimates of the relationship between exposure and the disease under study, by other factors that are related, both to disease and exposure. This confounding factor can affect the relationship or effect of exposure on the occurrence of disease that is estimated or predicted by the study is not the same as the relationship or effect that actually occurs in the target population, or the study results are invalid (incorrect).

Estimates of the combined association of oral hormonal contraceptives and injection to breast cancer were processed using the RevMan 5.3 application with the generic inverse variance method. This method is used to analyze data in the form of: rate, time-to-event, hazard ratio, ordinal scale, adjusted estimate, difference difference of mean or ratio of mean (Anulus et al. 2019). The results of the systematic review and meta-analysis of this study are presented in the form of forest plots and funnel plots.

The forest plot is a diagram that shows visually the amount of variation (heterogeneity), CI, the average between the results of the studies examined in the meta-analysis. A funnel plot is a diagram in meta-analysis used to demonstrate possible publication bias. The funnel plot shows the relationship between the effect size of the study and the sample size of the various studies studied, which can be measured in a number of different ways (Murti, 2018).

\section{Effect of Oral Hormonal Contracep- tives on Breast Cancer}

There are 15 research articles consisting of 5 cohort studies and 10 case control studies that serve as a source of meta-analysis of the effect of using oral hormonal contraceptives on the incidence of breast cancer. The results of the forest plot research article with a cohort observational design using subgroup analysis showed that the use of oral hormonal contraceptives had a 1.16 times risk of developing breast cancer compared to non-hormonal contraceptives and the results were statistically significant 
$(\mathrm{aOR}=1.16 ; 95 \% \mathrm{CI}=1.06$ to $1.26 ; \mathrm{p}=$ o.001). Meanwhile, a research article with a case control study using subgroup analysis showed that the use of oral hormonal contraceptives had a 1.48 times risk of developing breast cancer compared to nonhormonal contraceptives and the results were statistically significant $(\mathrm{aOR}=1.48$; $95 \% \mathrm{CI}=1.16$ to $1.90 ; \mathrm{p}=0.002$ ).

Systematic review and meta-analysis in this study were carried out with the aim of increasing the generalizability of the findings and obtaining convincing conclusions from various similar studies regarding the effect of oral hormonal contraceptives on breast cancer. Besides systematic review and meta-analysis in this study, the primary study used controls the confounding factor which can be seen from the research inclusion criteria, namely using an observational design and the statistical results reported are Adjusted Odds Ratio (aOR). However, there are confounding factors from several primary studies that are able to influence the actual effect relationship.

Confounding factor is a mixture of estimated associations between exposure and disease that is investigated by other factors that are associated with both disease and exposure. To be called a confounder a covariate must be a risk factor for disease in the unexposed base population not exposed to exposure. In other words: a confounder must be a risk factor for disease. Confounding factors affecting the relationship or effect of exposure to the occurrence of disease estimated by the study are not the same as the relationship or effect that actually occurs in the target population or the results of the study are invalid (Murti, 2018).

Hunter et al. (2010), in their research, stated that the current use of oral contraceptives has a greater risk of developing breast cancer. The levonorgestel used in triphasic preparations was responsible for the bulk of this increase in risk $(\mathrm{aOR}=1.12$; 95\% $\mathrm{CI}=0.95-1.33 ; \mathrm{p}=0.17$ ). Based on users of oral contraceptives, compared to users who have never before been used to contraception, current users of oral contraceptives are more likely to be nulliparous, and have no history or little duration of breastfeeding. The formulation contained in oral contraceptives significantly associated with an increased risk of ethinyl estradiol triphasic in combination with levonorgestrel was associated with an increased risk of breast cancer.

Bardaweel et al. (2019) found that regular use of oral contraceptives was associated with a statistically significant increase in breast cancer risk $(\mathrm{aOR}=2.25$; 95\% $\mathrm{CI}=1.34$ to $2.79 ; \mathrm{p}=0.002$ ). However, in terms of duration of use of oral contraceptives, this study was not associated with an increased risk of breast cancer ( $p>$ 0.05). Apart from this, other factors that also show a relationship in increasing breast cancer are puberty age, menopausal age, previous pregnancy, menopausal status and a family history of breast cancer.

Alsolami et al. (2019) stated that oral hormonal contraceptives were a significant factor in the occurrence of breast cancer $(\mathrm{aOR}=6.78 ; 95 \% \mathrm{CI}=3.42$ to $13.44 ; \mathrm{p}$ $<0.001)$. The female body during reproductive age can increase the risk of breast cancer, not least is the effect of synthetic hormones contained in hormonal contraceptives. The combined estrogen hormone in hormonal contraception has been identified in previous studies as the leading cause of breast cancer in women. This is in line with the research of Morch et al. (2018) who stated that the use of hormonal contraceptives had a 1.38 risk of developing breast cancer and was significantly proven with use of more than 10 years $(p=0.002)$. 
After stopping the use of hormonal contraceptives, the risk of breast cancer is still higher in women who have used hormonal contraceptives for 5 years or more than in women who do not use hormonal contraceptives.

\section{Effect of Injection Hormonal Contra- ceptives on Breast Cancer}

There are 6 research articles consisting of case control studies which serve as a source of meta-analysis of the effect of using injection hormonal contraceptives on the incidence of breast cancer. The results of the forest plot research article with observational case control design showed that the use of injectable hormonal contraceptives had a 1.37 times risk of developing breast cancer compared to non-hormonal contraceptives and the results were statistically significant $(\mathrm{aOR}=1.37 ; 95 \%$ $\mathrm{CI}=1.09$ to $1.71 ; \mathrm{p}=0.006$ ).

Systematic review and meta-analysis in this study were carried out with the aim of increasing the generalizability of the findings and obtaining convincing conclusions from various similar studies regarding the effect of injectable hormonal contraceptives on breast cancer. Besides systematic review and meta-analysis in this study, the primary study used controls the confounding factor which can be seen from the research inclusion criteria, namely using an observational design and the statistical results reported are Adjusted Odds Ratio (aOR). However, there are confounding factors from several primary studies that are able to influence the actual effect relationship.

Confounding factor is a mixture of estimated associations between exposure and disease that is investigated by other factors that are associated with both disease and exposure. To be called a confounder a covariate must be a risk factor for disease in the unexposed base population not exposed to exposure. In other words: a confounder must be a risk factor for disease. Confounding factors affecting the relationship or effect of exposure to the occurrence of disease estimated by the study are not the same as the relationship or effect that actually occurs in the target population or invalid study results (Murti, 2018).

The results of this study are supported by research by Moradinazar et al. (2019) which aims to determine the effect of factors related to fertility and hormone use on the risk of breast cancer in women under 50 years of age in Iran. In this study it was found that there was an association between the incidence of breast cancer and the use of hormones including the use of hormones for contraception and this association was stronger in women who used contraception for more than 10 years $(\mathrm{aOR}=2.02 ; 95 \% \mathrm{CI}=1.2-3.3 ; \mathrm{p}=0.008)$. Another study by Puri et al (2009) in Patel et al. (2015) also stated that $77.8 \%$ of women had used injectable hormonal contraceptives for more than one year ( $>1$ year) and consequently had a high risk of developing breast cancer. High doses of estrogen are associated with an increased risk of breast cancer, because of this the Western Kenyan government ensures that hormonal contraceptives are prescribed to women in Kenya at low doses.

In one of the primary studies with a case control study design, namely by Amadou et al. (2013) stated that the use of injectable hormonal contraceptives had a 1.22 times risk of developing breast cancer compared to those who did not use injectable hormonal contraceptives. Hormonal contraceptives usually contain the sex hormones estrogen and progesterone. These hormones have been reported to exert different effects on different tissues, but the exact mechanism associated with 
breast cancer is not completely clear. The hormone estrogen can increase the rate of cell division in the epithelium of the breast duct, and increase the possibility of mutations or promotion of existing mutations. And in addition, the progesterone and progestins contained in injectable hormonal contraceptives can increase this effect.

This is in line with Urban et al. (2012) who stated that the risk of breast cancer increased significantly among women who had used injectable contraceptives compared to those who never used hormonal contraceptives $\left(\mathrm{aOR}=1.31 ; 95 \% \mathrm{CI}=1.03^{-}\right.$ 1.65; $\mathrm{p}=0.028$ ). In this study, it was also stated that women who had both contraceptives, namely oral hormonal contraceptives and injection with a long duration of use had an effect on the incidence of breast cancer but it was not significantly related $(\mathrm{p}=0.40)$.

Li et al. (2012) showed that injectable contraceptives containing the same progestin as menopausal hormone therapy were found to increase the risk of breast cancer among post-menopausal women by 2.2 times compared with women who did not use injectable contraception $(\mathrm{aOR}=2.2$; 95\% CI= 1.2- 4.2; $\mathrm{p}=0.010$ ). This is in line with research conducted by Heikkinen et al. (2016) that there is a positive relationship between current use of hormonal contraceptives and the risk of breast cancer, more specifically in cases diagnosed in recent years.

In one of the primary studies with a case control study design, namely by Rispah et al (2015), it can be seen that the CI range is very wide ( 0.7 to 28.9). This can be caused by missing data during the follow-up process. This missing or missing data is likely to be data in the group exposed to positive risk factors, so this could lead to a weak association measure of $0.11 \mathrm{aOR}$ and a wide CI range. Meanwhile, another cause may be due to the number of samples that are too small.

In the case control study, there was also a publication bias of the results of the study of the 6 primary study articles. This is indicated by the asymmetry of the distribution between the left and right plots. On the left there are 3 plots while on the right plot there are also 3 plots but the distribution is not evenly distributed. The publication bias in case control studies as shown by the primary study articles is due to the relatively small number of samples $(n=$ 142). It also makes the CI range wide.

The results of the study on both variables showed a weak influence on the use or history of use of oral and injection hormonal contraceptives on the incidence of breast cancer and were statistically significant. However, a larger relationship size was indicated by the results of the variable oral hormonal contraception with a case-control observational study design $(\mathrm{aOR}=1.48 ; 95 \% \mathrm{CI}=1.16-1.90 ; \mathrm{p}=0.002)$. This could be due to the larger number of primary studies combined and the absence of underestimates due to loss to follow-up in the primary case control study.

In contrast to the results of the forest plot article with a cohort observational design which showed that oral hormonal contraceptives had a 1.16 times risk of developing breast cancer compared to those who did not use or did not have a history of oral hormonal contraceptives and the results were statistically significant $(\mathrm{aOR}=$ 1.16; 95\% CI = 1.06 - 1.26; $\mathrm{p}=0.001$ ). These results show that the aOR value is smaller when compared to the aOR value in case control studies on the variable oral hormonal contraception and the aOR value in case control studies on the variable injection hormonal contraception. This happens because the combined aOR value is not large enough. In addition, it could 
also be because the cohort primary study article had a large enough loss to follow-up in the exposed group which could have an effect on the results of the study so that the results were underestimates. In the results of the meta-analysis of this study, there are several confounding factors that are important to control by researchers such as the age of the respondent, the age of menarche and also a family history of breast cancer.

\section{AUTHOR CONTRIBUTION}

Dilma'aarij Riski Agustia is the main researcher who chose the topic, carried out a search for data collection in this study. Setryo Sri Rahardjo and Eti Poncorini conducted data analysis and research document review studies.

\section{CONFLICT OF INTEREST}

There is no conflict of interest in this study.

\section{FUNDING AND SPONSORSHIP}

This study is self-funded.

\section{ACKNOWLEDGEMENT}

Researchers would like to thank all those who helped compile this article and also thank the database providers PubMed, ScienceDirect, and Google Scholar.

\section{REFERENCE}

Alsolami FJ, Azzeh FS, Ghafouri KJ, Ghaith MM, Almaimani RA, Almasmoum HA, Abdulal RH,et al. (2019). Determinants of breast cancer in Saudi women from Makkah region: A casecontrol study (breast cancer risk factors among Saudi women). BMC Public Health, 19(1): 1-9. https://doi.org/10.1186/s12889-019-7942-3.

Amadou A, Fabre A, Torres MG, Ortega OC, AngelesLA, McKenzie F, BiessyC, et al. (2013). Hormonal therapy and risk of breast cancer in Mexican women. PLoS ONE, 8(11). https://doi.org/10.1371/journal.pone.0079695.

Ayu G, Dewi T, Hendrati LY, Ua FK (2015). Analisis risiko kanker payudara berdasar riwayat pemakaian kontrasepsi hormonal dan usia (Analysis of breast cancer risk based on history of hormonal contraceptive use and age). Periodic Epidemiol J. 3(1): 12-23. https://e-jour-

nal.unair.ac.id/JBE/article/download /1309/1068.

Bardaweel SK, Akour AA, Al-Muhaissen S, Alsalamat HA, Ammar K (2019). Oral contraceptive and breast cancer: Do benefits outweigh the risks? A case Control study from Jordan. BMC Women's Health, 19(1): 1-7. https://doi.org/10.1186/s12905-019-0770-x.

Busund M, Bugge NS, Braaten T, WaasethM, RylanderC, Lund E (2018). Progestin-only and combined oral contraceptives and receptordefined premenopausal breast cancer risk: The Norwegian Women and Cancer Study. Int J Cancer.142(11): 2293-2302.

https://doi.org/10.1002/ijc.31266.

CEBMa (2014). Critical Appraisal for crosssectional study. Amsterdam.

Globocan (2020). Indonesia - Global cancer observatory. WHO; Int Agency for Res on Cancer, 2018. Available at: https://gco.iarc.fr/today/data/factshe ets/populations/360-indonesia-factsheets.pdf.

Heikkinen S, Koskenvuo M, Malila N, Sarkeala T, Pukkala E, Pitkaniemi J. (2016). Use of exogenous hormones and the risk of breast cancer: results from self-reported survey data with validity assessment. Cancer Causes and Control, 27(2): 249-258. https://doi.org/10.1007/s10552-015-0702- 
Dilma'aarij et al./ The Effect of Oral and Injection Contraceptives on Breast Cancer

5 .

Kemenkes (2015). Panduan Penatalaksanaan Kanker Payudara (Breast Cancer Management Guide). Kementerian Kesehatan Republik Indonesia. 1-50. Available at: http://kanker.kemkes.go.id/guidelines/PPKPayudara.pdf.

Kemenkes RI (2019). Profil Kesehatan Indoneisa 2019, Kementerian Kesehatan Republik Indonesia.

Kemenkes RI (2019) Profil Kesehatan Indonesia 2018 [Indonesia Health Profile 2018]. Available at: http://www.depkes.go.id/resources/download/pusdat in/profil-kesehatan-indonesia/Datadan-Informasi_Profil-KesehatanIndonesia-2018.pdf.

Kementerian Kesehatan RI Badan Penelitian dan Pengembangan (2018). Hasil Utama Riset Kesehatan Dasar, Kementrian Kesehatan Republik Indonesia. Available at: http://www.depkes.go.id/resources/download/infoterkini/hasil-riskesdas-2018.pdf.

Li CI, Beaber EF, Tzue M, Tang C, Porter PL, Daling JR, Malone KE (2012). Effect of depo-medroxyprogesterone acetate on breast cancer risk among women 20 to 44 years of age. Blood Cancer Discov, 72(6). 2028-2036. doi: 10.1158/0008-5472.CAN-11-4064 .

Moradinazar M, Marzbani B, Shahebrahimi K, Shahabadi S, Marzbani B, Moradinazar Z (2019). Hormone therapy and factors affecting fertility of women under 50-year-old with breast cancer. Breast Cancer: Targets and Therapy, 11: 309-319. doi: 10.2147/BCTT.S218394.

Morch LS, Skovlund CW, Hannaford PC, Iversen L, Fielding S, Lidegaard $\mathrm{O}$
(2018). Contemporary hormonal contraception and the risk of breast cancer. New Eng J Med. 377(23): 2228-2239.https://doi.org/10.1056/NEJMoa1700732.

Murti B (2018). Prinsip dan metode riset epidemiologi (Principles and methods of epidemiological research). $5^{\text {th }}$ Edition. Surakarta: Program Studi Ilmu Kesehatan Masyarakat.

Patel K, Moi U, Torrorey R, Rono S, Eldoret U, Lugaria L, Busakhala N (2015). Risk factors associated with aggressive breast cancer forms seen in young women of Western Kenya. J Med Sci Clin Res. 3(5): 5857-5867. https://doi.org/10.13140/RG.2.2.1511 4.29120.

Shapiro S, Rosenberg L, Hoffman M, Truter H, Cooper D, Rao S, Dent D, et al. (2021). Risk of breast cancer in relation to the use of injectable progestogen contraceptives and combined estrogen/progestogen contraceptives. Am J of Epidemiol, 151(4): 396403.doi: 10.1093/oxfordjournals.aje.a010219.

Urban M, Banks E, Egger S, Canfell K, Connell D, Beral V,Sitas F (2012). Injectable and oral contraceptive use and cancers of the breast, cervix, ovary, and endometrium in black South African women: Case-control study. PLoS Med, 9(3): 1-12. https://doi.org/10.1371/journal.pmed.1001 182.

Yulianti I (2016). Faktor-faktor risiko kanker payudara. J Public Health, 4. Available at: https://ejournal3.undip.ac.id/index.php/jkm/article/view/14 162. 